\title{
Effects of Vocabulary Knowledge and Translating Competence on the Comprehensive English Ability
}

\author{
Shang-chun ZENG ${ }^{1}$ and Ying SHEN ${ }^{2, *}$ \\ ${ }^{1}$ College of International Exchange, Wuzhou University, Guangxi, China \\ ${ }^{2}$ Foreign Languages College, Guangxi University, Guangxi, China \\ Institute for Intelligent Systems, the University of Memphis, TN USA
}

${ }^{*}$ Corresponding author: Ying Shen

Keywords: Productive vocabulary size, Receptive vocabulary size, Regression analysis, Translating competence.

\begin{abstract}
The purpose of this thesis is to reveal the characteristics of participants' vocabulary size and their translating competence as well as the correlation between their vocabulary size and their comprehensive English ability, the correlation between their translating competence and comprehensive English ability. Eighty-two junior English majors from Wuzhou University took the Productive Vocabulary Levels Test, Receptive Vocabulary Levels Test and China Accreditation Test for Translator (CATT) mock test Level 3. All of their scores of TEM-4 were analyzed via SPSS16.0. The findings are as follows: 1) Participants performed better in receptive vocabulary size test than in productive vocabulary size; 2) There is significant correlation between participants' productive vocabulary size and their comprehensive English ability; 3) Participants' productive vocabulary size can predict $19 \%$ of changes of their comprehensive English ability of the 3000 vocabulary frequency bands, and of the 5000 vocabulary frequency bands, the percentage is $39.5 \%$; 4) For the correlation between participants' translating competence and their comprehensive English ability, the significance does exist; 5) Participant's English-Chinese translating competence can predict $19.8 \%$ of changes of their comprehensive English ability, while participants' Chinese-English translating competence can predict $14.5 \%$ of changes of their comprehensive English ability.
\end{abstract}

\section{Introduction}

In the field of EFL learning, vocabulary had not been viewed as an important role until the 1960s, and at that period, people believed that learning from grammar was more important than vocabulary in language leaning. However, since the 1980s, researchers and scholars have recognized the importance of vocabulary. It can be easily seen that the significance of vocabulary learning has been emphasized. Many researchers think that vocabulary occupies the most essential part in influencing students' comprehensive English ability.

The current research investigates English majors' vocabulary knowledge from one of the aspects of vocabulary knowledge, that is, vocabulary size, and tries to figure out the relationship between vocabulary size and comprehensive English ability of English majors on the basis of an empirical study.

This research includes three purposes as follows:

(1) Investigating the English majors' receptive and productive vocabulary knowledge and then reveals the characteristics of their receptive and productive vocabulary knowledge.

(2) Figuring out the English major's translating competence and then reveals the characteristics of their translating competence. 
(3) Managing to find out the correlation between English majors' vocabulary knowledge and their comprehensive English ability as well as the correlation between English majors' translating competence and their comprehensive English ability.

\section{Research Methodology}

\section{Research Questions}

This research mainly consists of six questions as follows:

What are the characteristics of participants' receptive and productive vocabulary knowledge?

(1) What are the characteristics of participants' comprehensive English ability?

(2) To what extent is vocabulary size associated with the comprehensive English ability?

(3) What are the characteristics of participants' translating competence (English-Chinese translating)?

(4) What are the characteristics of participants' translating competence (Chinese-English translating)?

(5) To what extent is participants' translating competence associated with their comprehensive English ability?

\section{Research Participants}

The participants were 82 third-year English majors in three classes from Wuzhou University. Because Wuzhou University enrolls students from different cities and provinces nationwide in China, the test scores of the participants can be representative to some degree.

\section{Research Instruments}

Productive Vocabulary Levels Test, Receptive Vocabulary Level Test, China Accreditation Test for Translators -Level 3 Mock Test (CATT-Level 3 Mock Test) and Test for English Majors-4 (TEM-4) serve as the instruments of this study.

\section{Receptive Vocabulary Level Test}

The Receptive Vocabulary Level Test adopts a format of form-recognition matching. In the format, the stem is the definition, the options are the target words. Three stems and six options are included in each cluster of items. In the latest Schmitt's version (2010:197), each level has ten clusters (i.e. 30 items).

\section{Productive Vocabulary Levels Test}

The current research uses the Productive Levels Test (Schmitt, 1999:36-55) to measure the participants' productive vocabulary knowledge. As the same reason taken into consideration, this research only tests vocabularies on 3000 and 5000 word frequency levels. The total score of 3000 word frequency levels is 18 points and the total score of 5000 word frequency levels is the same.

\section{China Accreditation Test for Translators (CATT) Mock Test Level 3}

CATTI, which stands for China Accreditation Test for Translator and Interpreters, is designed for the would-be professional or professional translators or interpreters to assess their 
proficiency and competence in translation and interpretation. It was launched by the Ministry of Personnel of the People's Republic of China since the year 2003. CATTI is considered as an authoritative and effective accreditation test for test takers' bilingual translating or interpreting competence.

The test takers who are with basic scientific and cultural knowledge and a general competence for bilingual translation can be regarded as the translator of Level 3. Level 3 translator can accomplish general translation task.

\section{Test for English Majors-4 (TEM-4)}

Test for English Majors-4 (TEM-4) is an important test for English majors, which is designed to valuate how well the English majors master the knowledge after they finish the learning tasks in the primary state according to the requirement set by National English-teaching Curriculum for English Majors at Universities (NECEMU).

\section{Results and Discussions}

\section{Descriptive Statistics of the Receptive Vocabulary of 3000 Vocabulary Frequency Bands}

The total score of the receptive vocabulary levels test of 3000 word frequency level was 30 . It can be seen that the minimum score of the receptive vocabulary levels test of 3000 word frequency was 0 while the maximum score was 30 . This indicates that among the participants, a few of them were excellent in this level because a few of them may fail to master the words in the 3000 word level. For the average score was around 22.13, accounting for $73.77 \%$, this can suggest that among all the participants, most of them can master words in the 3000 word frequency level from the perspective of reception.

\section{Descriptive Statistics of the Receptive Vocabulary of 5000 Vocabulary Frequency Bands}

The minimum score of the 5000 word frequency level was higher than that of the 3000 word frequency level, while the maximum score was the same. The average score of the 5000 word frequency level test was around 19.36, accounting for $64.53 \%$ compared with the accuracy rate of $73.77 \%$ in the 3000 word frequency levels test. A drop can be seen in the 5000 word level. This result informs us that participants mastered the most frequent and core meanings of the words better in the 3000 word level than in 5000 word level.

\section{Characteristics of Participants' Receptive Vocabulary Knowledge}

It can be inferred that the receptive vocabulary size that the participants have mastered in the current research was not big in as what had been stated by Gui's research (1985:1-6), which estimated that the average vocabulary size of freshman English major is 2000, and after two years learning, the vocabulary size of English majors can be roughly estimated as 5000 .

\section{Descriptive Statistics of the Comprehensive English Ability of English Majors}

The total scores of TEM-4 was 100. The overall performance of participants in the TEM-4 was not good enough with the maximum score was 75 and the minimum score was 35 and the 
mean score was around $51.78(<60)$. This result indicated that a large number of participants cannot master the language skills required in the National English-teaching Curriculum for English Majors in Universities (NECEMU).

\section{Correlations between Receptive Vocabulary Size and Comprehensive English Ability of English Majors}

The result indicated that 1) The correlation between receptive vocabulary of 3000 word level and comprehensive English ability was not significant with $r=0.221$ in the second level; 2) The correlation between receptive vocabulary of 5000 word level and comprehensive English ability was not significant with $r=0.268$. But compared with the correlation between receptive vocabulary of 3000 word level and comprehensive English ability $(\mathrm{r}=0.221)$, the significance of the correlation was slightly higher $(r=0.268>r=0.221)$.

\section{Descriptive Statistics of the Productive Vocabulary of 3000 Vocabulary Frequency Bands}

The total score of the productive vocabulary levels test of 3000 word frequency level was 18 . The minimum score of the productive vocabulary levels test of 5000 word frequency was 0 , while the maximum score was 16 . This indicated that a few of participants are excellent in this level while some may fail to master the words in the 5000 word level. The average score was around 7.11 , accounting for $39.5 \%$. This result told us that most of the participants cannot produce words when prompted by a task of the 3000 word frequency level.

\section{Descriptive Statistics of the Productive Vocabulary of 5000 Vocabulary Frequency Bands}

The total score of the productive vocabulary levels test of 5000 word frequency level was 18 , the same as that of 3000 word level. The minimum score was the same as that in the 5000 word frequency level, while the maximum score in the 5000 word frequency level was much lower than that of 3000 word level, with a score of 9 point, accounting for $50 \%$. The result informed that that all the participants had a poor performance at this level.

\section{Correlations between Productive Vocabulary Size and Comprehensive English Ability of English Majors}

The result indicated that the correlation between productive vocabulary of 3000 word level and comprehensive English ability was significant with $r=0.434$ in the third level. Thus, it is evident that the productive vocabulary size of 3000 word level of participants is closely linked with their comprehensive English ability.

\section{Regression Analysis}

The statistical result showed that two independent variables had significant correlations $(\mathrm{p} \leq 0.01)$. As $\mathrm{R}$ Square $=.190$, it is clear that the independent variable productive vocabulary size of 3000 vocabulary frequency bands can predict $19 \%$ changes of the dependent variable of the comprehensive English ability. 


\section{Descriptive Statistics of the Translating Competence (English-Chinese Translating) of English Majors}

The total score of the translating test (English-Chinese) was 50. The minimum score of the translating test was 24 while the maximum score was 42 . There is a big gap between the two. The mean score was around 33.7 accounting for $67.4 \%$. This meant that a large number of the participants did not perform well in the translating test.

\section{Correlations between Translating Competence and Comprehensive English Ability of English Majors}

The result revealed an exact significance existed in the correlation between participants English-Chinese translating competence. It is not surprising to get the result, for according to the definition of translating competence, most scholars defined that linguistic competence is of great importance to language learners' translating competence. It can be said that with the development of participants' translating competence, the participants' comprehensive English ability will be enhanced.

\section{Descriptive Statistics of the Translating Competence (Chinese -English Translating) of English Majors}

The total score of the translating test (Chinese-English) was 50. The minimum score of the translating test was 32 while the maximum score was 42 . The minimum score was higher than that in English-Chinese translating test $(32>24)$, and the maximum score was the same. It appeared clearly that participants did a little better in English-Chinese translating than in Chinese-English translating.

\section{Correlations between Translating Competence and Comprehensive English Ability of English Majors}

The result revealed that an exact significance existed in the correlation between participants' Chinese-English translating competence and their comprehensive English ability. This result went in line with what Laufer, (1996 \& 1998) had found. It is found that linguistic competence is of great importance to language learners' translating competence.

\section{Regression Analysis}

The comprehensive English ability was set as a dependent variable, the translating competence (English-Chinese translating) and translating competence (Chinese-English translating) were set as independent variables. The statistics showed that $\mathrm{R}$ Square $=.198$ when the independent variable was set as translating competence (English-Chinese translating) and the dependent variable was set as comprehensive English ability. This result indicated that the independent variable can predict $19.8 \%$ changes of the dependent variable. And when the comprehensive English ability was set as a dependent variable again, and the translating competence (Chinese-English translating) was set as the independent variable, the percentage was low in predicting changes ( $\mathrm{R}$ Square $=.145$ ). This finding told us that the independent variable can predict $14.5 \%$ changes of the dependent variable. 


\section{Conclusions}

Vocabulary is essential to language learning. The current research revealed that the vocabulary size of the participants was low either from the perspective of receptive vocabulary knowledge or productive vocabulary knowledge. But in general, participants performed better in the receptive vocabulary size test than the productive vocabulary size.

The correlation between receptive vocabulary size and the comprehensive English ability was of low significance, the correlation between productive vocabulary and the comprehensive English ability was of the greatest significance among others (0.626). Thus, the current research verified that vocabulary is closely linked with English majors' comprehensive English ability from the perspective of productive vocabulary knowledge, which means to master a large vocabulary size can help students to perform better in their language learning.

It is also evident that the correlation between English majors' translating competence and their comprehensive English ability was significance. This finding proved that there is a close correlation between vocabulary size and comprehensive English ability of English majors, as well as a correlation between translating competence and English majors' comprehensive English ability.

\section{Acknowledgment}

This research is financially supported by the following research foundations:

(1) Innovative Research Foundation for National University Students in 2014 (Grant NO.141059349).

(2) Distinguished University Teachers' Overseas Detachment Foundation in 2014-2015 from Guangxi Higher Education Bureau.

\section{References}

[1] B. Laufer. The lexical threshold of second language reading comprehension: what it is and how it relates to L1 reading ability. In Kari Sajavaara \& C. Fairweather (Eds.). Approaches to Second Language Acquisition. Jyvaskyla: University of Jyvaskyla, 1996, pp. 55-62.

[2] B. Laufer. The development of passive and active vocabulary in a second language: same or different?. Applied Linguistics (2):1998, pp. 255-27.

[3] N. Schmitt and B. Dunham. Exploring native and nonnative intuitions of word frequency. Second Language Research 15 (2), 1999, pp. 389-411.

[4] N. Schmitt. Researching Vocabulary. Houndmills: Palgrave Macmillan, 2010.

[5] S. C. Gui. Investigation and analysis on the vocabulary size of English majors in China, Modern Foreign Languages (1), 1985, pp. 1-6. 